\title{
The Impact of Prolonged Sitting Hours on the Correct Standing up Position of Elementary School Students in Developed Rural Area
}

\author{
EMANUELA GEORGIANA GAL-NADASAN ${ }^{1}$, NORBERT GAL-NADASAN ${ }^{2}$, DAN V. POENARU ${ }^{3}$, DAN SURDUCAN ${ }^{1}$, \\ DIANA POPA-ANDREI ${ }^{1}$, MADALINA CASIANA-SALAVAT (PALFI) ${ }^{4}$, MADALINA VERONICA BORUGA ${ }^{1}$, \\ BOGDAN NICULESCU ${ }^{5 *}$, TIBERIU TATARU ${ }^{5 *}$ \\ ${ }^{1}$ University of Medicine and Pharmacy Victor Babes, 2 Eftimie Murgu Sq., 300041, Timisoara, Romania \\ ${ }^{2}$ Politehnica University of Timisoara, Department of Automation and Applied Informatics, 2 Victoriei Sq., 300006, Timisoara, Romania \\ ${ }^{3}$ University of Medicine and Pharmacy Victor Babes, Clinic II of Orthopedic and Traumatology Department, 2 Eftimie Murgu Sq., 300041 , Timisoara, \\ Romania \\ ${ }^{4}$ University of Medicine and Pharmacy Victor Babes, Clinic of Ophthalmology Department, 2 Eftimie Murgu Sq., 300041, Timisoara, Romania \\ ${ }^{5}$ University Constantin Brancusi, 30 Calea Eroilor, 210135, Targu Jiu, Romania
}

At young ages the spinal column, which is the central support system of the human body, is susceptible to malformations, especially if the children are sitting in an incorrect position for long period. Our study examines the case of several elementary school students from a developed rural area. The aim of this study to analyze the impact of long sitting hours (5-6 hours) in incorrect position at on the normal standing up position at elementary school students. The study group for our study consisted of 80 elementary school students were recruited from a local rural elementary school. Each student was evaluated using a Kinect based system to determine their general standing up position. For 14 weeks, twice a week, each student has executed 5 type of Schroth exercises to improve their general body position. The first evaluation has shown that the students general standing up position is affected from the long sitting hours in the school benches. Most of them have shown misalignments at the shoulder and hip levels. In many cases one of the shoulders was higher than the other and the same is true for the hips as well. After 14 weeks of physiotherapy based on Schroth exercises the miss alignments were reduced to a bare minim. The results have shown that long sitting hours in incorrect positions can affect the spinal column and the standing up posture of the human body. In many cases malicious postures start to develop from childhood. If not treated they can transform in hyper-kyphotic and scoliotic postures which can induce other complications. If these malicious postures are observed in early stages of the children and with only 2 hours a week of physiotherapy based on Schroth exercise the postures can be corrected and the hyper-kyphotic and scoliotic postures can be avoided.

Keywords: standing up position, Schroth exercises, spinal column

The spinal column represents the axial support element of the human body. The spinal column is made up of bones called vertebrae. The spinal column is made up of 31 segments: 8 cervical, 12 thoracic, 5 lumbar, 5 sacral and 4-5 coccygeal [1]. The vertebrae from the cervical, thoracic and lumbar section are independent one from another providing better mobility for de spinal cord. The vertebrae from the sacral and coccygeal segments are fused having lower mobility. In general, the spinal cord has an average length of $63 \mathrm{~cm}$ at females and $73 \mathrm{~cm}$ for males. This length represents $40 \%$ of a person's height.

The spinal cord can develop two types of curvatures: one curvature on the sagittal plane and one curvature on the frontal plane. The sagittal curvatures are called lordosis and kyphosis. The lordosis is the normal inward curvature of lumbar and cervical region. The kyphosis is the normal outward curvature in the thoracic and sacral regions. If these normal curvatures are exaggerated hyper-scoliosis and hype-kyphosis can appear [2,3].

The spinal column in the human body has three important functional roles:

-The protection of the spinal cord. This is achieved by the bone layer of the vertebral canal. This is formed by overlapping hollow interior structure of the vertebral bodies and spinal arches of the vertebrae.

-The support of the upper body: In standing up position the spinal column has the function of supporting the head, trunk and upper limbs by channelling the whole weight of the upper body to the lower limbs. The amplification of the spinal cord's natural curvatures can lead to pathological curvatures. The accentuation of the posterior convexity of the spinal cord is the characteristics of the hyper-kyphosis. The accentuation of the anterior convexity of the cord is the characteristics of the hyper-lordosis. These spinal pathological curvatures can be hereditary or developed over time. These pathological curvatures can affect the normal functions of the vital organs.

-Biomechanical role: The third role of the spinal column is to ensure the mobility of the upper body. Because of its unique structure the trunk of the body can execute numerous and ample movements.

*email: niculescu.bogdan@utgjiu.ro; tatarutiberiu@gmail.com 
The spinal column can develop several type of abnormalities [4]:

-Chondromas: These are benign cartilaginous tumors developed on congenital remains of the notochord [5].

-Spina bifida or posterior rachischisis is a malformation characterized by lack of spinal cord and incomplete closure of the neural tube in that region. It has an increased frequency in the lower lumbar region and the sacral region [6].

-Rachischisis anterior is the ventral longitudinal cleft of some vertebral bodies [7].

-Spondiloschizis is the lack of union or sinostosis of the vertebral arch with the vertebral body [8].

-Congenital platispondilia [9] occurs by stopping the growth of the vertebral body, and hemivertebra is the development of only half the vertebra.

Scoliosis is a chronic, evolutionary disease over time characterized by one or more lateral curvature of the spinal column. These vertebral column curvatures are observable in the frontal plane, being associated with the rotation of the vertebrae. This pathology (scoliosis) has a major impact on the morphology and functionality of the human body. Over time there are important repercussions for the whole organism [10]. It affects between 3\% and 30\% of the population. The incidence of scoliosis increases with the persons age [11]. Scoliosis does not have a well established etiology. In the last studies, a particular role of genetics is identified, it is assumed that the chromosomes $6,9,16,17$ are involved in the case of idiopathic scoliosis [11]. The appearance of scoliosis can also be determined by the following factors: growth hormone secretion, connective tissue structure, adrenal dysfunction, thyroid dysfunction, vestibular dysfunction, melatonin secretion, a microcittic platelets structure and a propioceptive mechanism failure of patients [12]. The Hueter-Volkmann principle points out that some compressive forces are involved in skeletal deformations, thus preventing it from increasing, and by reducing these forces an acceleration of skeletal growth occurs $[13,14]$.

\section{Scoliosis classification:}

-Non-structural / functional scoliosis includes the following types of scoliosis: postural, compensatory, professional, from hearing disorders, vision and from vertebral body tumors.I

-Transient scoliosis includes scoliosis types that are reduced by treatment of the underlying disease, sciatic scoliosis, antalgic, vertebral backbone carditis, scoliosis from hysteria and scoliosis of inflammatory nature [15]

\section{Structural scoliosis:}

Congenital Scoliosis:

-It is an abnormal development of the spine, generated by incorrect formation of the vertebrae. This error occurs during embryo formation sometime very early in the first six weeks of the embryo. There are no specific studies to criminalize the fact that congenital scoliosis is transmitted within the family. Depending on the symptomatology generated by this congenital scoliosis, it can be discovered at birth, in childhood, and sometimes even in adolescence or at maturity [16]

Idiopathic scoliosis:

-Infantile scoliosis: In this category are the scoliosis diagnosed after birth until the age of 3 years. Approximately $1 \%$ of the diagnosed idiotic scoliosis is included here, and $60 \%$ of the patients are male. This type of scoliosis involves two etiologies: the first to criminalize a bending of the spine from birth with a progressive worsening of it, and the second theory suggests that a child who slept in the dorsal decubitus will develop both plagiocephaly and scoliosis. There are more cases of progressive scoliosis in Europe than in the United States, suggesting genetic involvement in the appearance of scoliosis. Infantile scoliosis is associated with congenital hip dysplasia, mental deficiency, plagiocephaly and congenital heart defects [17]

-Juvenile scoliosis: Juvenile scoliosis is diagnosed for the first time in children with age 3 to 10 years. This scoliosis comprises $10 \%-15 \%$ of idiopathic scoliosis diagnosed at children. At the beginning of this period, boys are mostly affected, and at the end of this decade the female population is more affected [18].

-Idiopathic scoliosis of the teenagers starts between 10-18 years.

- Neuromuscular scoliosis is favored by the injury of the superior motor neuron in the following diseases: cerebral palsy, Friedreich's ataxia, Charcot-Marie-Tooth disease, spinal cord injuries, spinal cord tumors, siringomielia, Roussy-Levy syndrome, and lower motor neuron injury of the following diseases: poliomyelitis, viral meningitis, Riley-Day syndrome, muscle dystrophy [19] and in myotonic dystrophy, congenital hypotonia, myelomeningocelulus and spina bifida.

- Musculoskeletal scoliosis may be caused by: lower limb symmetry, congenital hip dysplasia, imperfect osteogenesis, Klippel-Feil Syndrome.

Favoring factors: Incorrect and prolonged time in sitting position of the children, inadequate weight of the schoolbag, wearing the backpack on a single shoulder, ophthalmic pathologies not having optic correction, lack of physical activity with high Body Mass Index (BMI) and decreased muscle tone

The treatment of medical recovery is represented in children of physiotherapy. 
The goals of medical recovery are: to reduce pain, increase mobility, increase flexibility, tonify the paravertebral and abdominal muscles, acquire a correct posture, maintain the right posture throughout the day, make daily activities easier and painless, adjust daily activities and the environment working on sickness, conducting the physiotherapy program at home [20].

\section{Physiotherapy}

Through classical physiotherapy, the patient can [21]: Get rid of pain and functional limitations, prevent aggravation of spinal pathology during hormonal imbalances, stabilize spinal curvature, increase muscle tone and daily activity, improve proprioception, increase resistance to effort.

Types of exercises used in scoliosis:

-Symmetrical exercises, through which they try the stretching of the abdominal muscles,

-Breathing exercises, they aim at increasing the lung capacity and increasing the mobility and flexibility of the chest,

-Asymmetric exercises, they aim at elongation of the shortened and contracted muscles,

Static exercises: these are tractions and hangs, they aim at reducing tension in the spine.

\section{Objective}

The aim of this study to analyze the impact of long sitting hours (5-6 hours) in incorrect position at elementary school students on their normal standing up position. The secondary aim is to find a solution to neutralize the affects of long sitting hours and to correct the malicious standing up posture by applying physiotherapy using Schroth type exercises applied twice a week.

\section{Experimental part}

\section{Materials and methods}

To conduct our study a sample of 80 elementary school students were recruited from a local rural elementary school. The sex distribution of the students was the following: 30 male students and 50 female students between the ages of 11 and 15.

Each participant's parent signed a written medical informatory consent and a written consent in accordance with the Romanian GDPR legislation [22] Form the original sample group 2 male students and 3 female students were excluded due to the fact that they come in black clothes that rendered the data accusation impossible. The leggings and shirts worn by the students were black colored, color which absorbs the infrared scanning light emitted by the 3D scanner rendering the scanning impossible. The final age and sex distribution of the study sample is presented in Table 1.

Table 1

THE AGE AND SEX DISTRIBUTION OF THE STUDY GROUP

\begin{tabular}{|c|c|r|r|r|c|}
\hline Sex & $\begin{array}{r}11 \\
\text { years }\end{array}$ & $\begin{array}{r}\mathbf{1 2} \\
\text { years }\end{array}$ & $\begin{array}{r}\mathbf{1 3} \\
\text { years }\end{array}$ & $\begin{array}{r}\mathbf{1 4} \\
\text { years }\end{array}$ & $\begin{array}{r}15 \\
\text { years }\end{array}$ \\
\hline Male & 1 & 6 & 10 & 8 & 3 \\
\hline Female & 1 & 16 & 17 & 11 & 2 \\
\hline
\end{tabular}

Because the selected group is consisted of elementary school students wee need to take in consideration several other factors as well. We have selected the height and body mas index of the students to identify the scale of obesity among the participants in the study. The sex and height distribution are presented in table 2 and the body mass index sex distribution is presented in table 3 .

Table 2

THE SEX AND HEIGHT DISTRIBUTION OF THE STUDY GROUP

\begin{tabular}{|c|c|c|c|c|}
\hline Sex & $\begin{array}{c}\mathbf{1 . 4 0 - 1 5 0} \\
\mathbf{m}\end{array}$ & $\begin{array}{c}\mathbf{1 . 5 1 -} \\
\mathbf{1 . 6 0 m}\end{array}$ & $\begin{array}{c}\mathbf{1 . 6 1 -} \\
\mathbf{1 . 7 0 m}\end{array}$ & $\begin{array}{l}\mathbf{1 . 7 0 +} \\
\mathbf{m}\end{array}$ \\
\hline Male & 2 & 3 & 12 & 8 \\
\hline Female & 6 & 9 & 23 & 2 \\
\hline
\end{tabular}

Table 3

THE SEX AND BODY MAS INDEX DISTRIBUTION OF THE STUDY GROUP

\begin{tabular}{|c|c|c|c|}
\hline Sex & $\begin{array}{c}12- \\
17 \text { (underweight) }\end{array}$ & $17.1-23$ (normal) & $\begin{array}{c}23.1+ \\
\text { (overweight) }\end{array}$ \\
\hline Male & 2 & 19 & 7 \\
\hline Female & 9 & 32 & 6 \\
\hline
\end{tabular}




\section{Physiotherapy exercises}

For the physiotherapy exercises the Schroth [23] method has been chosen. This type of therapy divides the upper trunk in 3 separate blocks (cervical, thoracic and lumbar) that can be moved against one another [23]. This method can correct the kyphotic and scoliotic postures by mirror monitoring and proprioceptive and exteroceptive stimulation. The exercises are based on the self-elongation of the spinal column, corrective breathing and muscle memory re-education to improve the overall upper body posture. This is achieved by changing the breathing patterns. By using a mirror, the patient can view itself and monitor how the malicious posture changes into a normal posture.

The exercises which were prescribed for the patients are described below. There are 5 type of exercises that focuses on the hyper-kyphotic and scoliotic postures.

1) The patient is in squatting position on the wall bars: the feet are on the second bar of the wall bars and the hands are positioned apart on the bar at the shoulder level.

-To correct the hyper-kyphosis: the patient must execute the following movements: extend the legs, lower the buttocks and rock it gently back and forth and back to the starting position. Repeat this type of movement at least 5 to 10 times. It is recommended to move the hands to the lower bars and bring the buttocks as close to the ground as fast as possible with the legs extended.

-To correct the scoliosis: in the position described above guide the hip below the rib hump laterally, backwards and downwards to move the trunk into an oblique position. Keep this position during the movements described above. This widens the concave side of the spinal column.

2) In an abducted position on the wall bars with the hands holding the bars at shoulder height the pelvis is moved backwards with an extended back.

-To correct the hyper-kyphosis: elongate the trunk during inhalation. During exhalation the elbows are flexed and moved to the sides. Meanwhile, the back is kept stretched and the neck does not show lordosis. The head must touch the bar on which the hands rest. A minimal of 10 repetitions are required.

-To correct the scoliosis: while aligning the pelvis, raise the upper body and head towards the concave side. The hip on the convex side starts a counteraction and the narrow front moves forward and upwards. This has the effect of widening the concave side. A minimal of 10 repetitions are required.

3) Sitting cross legged with the back towards to the wall bars. They are grasping high and far apart, the elbows are slightly bent. In this position the lumbar and cervical lordosis are extended. The head can rest against a small board (optional).

-To correct the hyper-kyphosis: During inhalation the hands pull strongly downwards while the head is pushed upwards and the sides must be stretched. During exhalation the head pushes backwards while the upper back moves away from the wall bars and the chest moves forwards.

-To correct the scoliosis: the pelvis shifts towards the side of the rib hump, if is necessary corrective cushions can be put under and behind of the hip on the concave side. The upper body must be moved towards the concave side. Breathing: the convex side is pushed forward and upwards. The posterior concavities are pushed to the side, upwards and backwards. Maintain the resulting position and move the thorax away from the bars during exhalation.

4) Sitting upright in front of a mirror, one pole is held in each hand in upright position with the elbows spread wide above the shoulder height.

-To correct the hyper-kyphosis: the spine is moved upwards in a small serpentine movement and the is pulled upwards. The trunk is lifted out of the pelvis. Once the best possible height is achieved the flowing movements are executed: on inhalation the sides are pushed laterally and upwards, the lumber are backwards and upwards and the clavicles are pushed forwards and upwards. During exhalation the position should be stabilized and should be improved with each breath.

-To correct the scoliosis: bodyweight must be shifted to the concave side and the pelvis and shoulder gridle derotated. Incline the head towards the concave side and turn chin to the convex side combined with an occipital push. Before tensioning the all muscles to form a muscle mantle the concave side must be arched as far as possible across the hip and rotated backwards. Contraction during exhalation must be strong enough to lift the body from the floor.

5) Sitting upright on the floor in front of the mirror the hands are folded behind the head pulling it forwards to stretch the neck.

-To correct the scoliosis: the head pushes against the hands. The elbows are spread as far apart as possible to permit optimal widening of the chest. When the hands are removed the head can be tilted backwards. 
These exercises were executed by the elementary school students two times a week for one school semesters (14 weeks) at the physical education courses with 3 weeks of school break. The goal was to determine how much the students posture improves during this period.

\section{Data acquisition}

To represent using a digital model the orthostatic posture of the high school students we have chosen to scan the students using the Microsoft Kinect scanner. This scanner can create a digital skeleton of the scanned person without attaching any markers on the scanned subject. To detect if the scanned student may have a malicious posture the height and depth of each shoulder and hips were measured individually and a difference between these measurements were computed. These values were recorded in two steps: first step was to record the values while the patient was facing the scanner and in the second step the patient was standing with his back facing the scanner.

The Kinect is a system complementary to those existing and known [24] using expensive medical equipment and radiant. This is an optical system that can identify the major joints of the human body using an infrared laser. Each major joint in the body has assigned numeric values assigned three position in space. Using these spatial data the system generates a virtual skeleton of the patient and using the data above we can achieve a graphical representation of posture. This graphical representation and major joints recognized by Kinect are shown in figure 1.

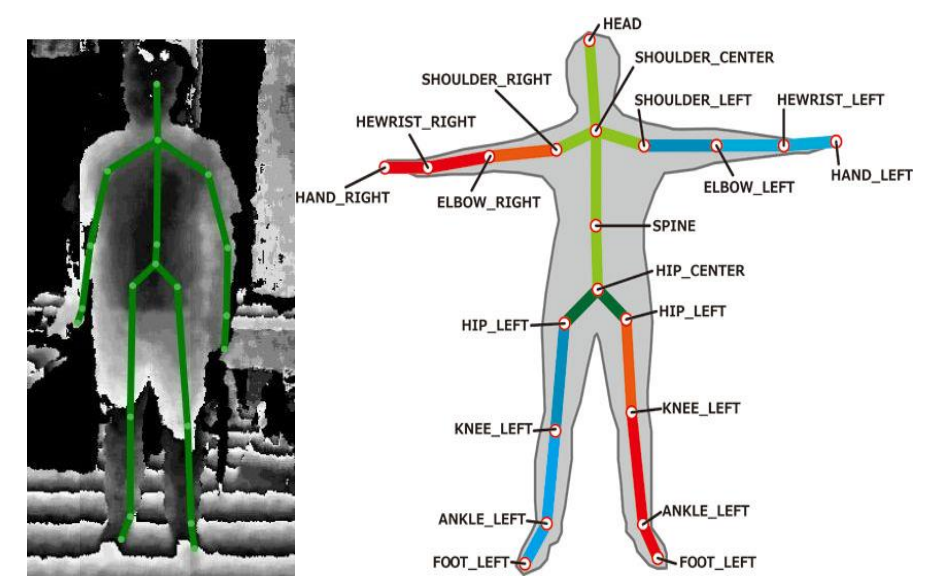

Fig. 1. Virtual skeleton made by Kinect and the recognized major joints

Previous studies show that even if the sensor Kinect has an optimal price, it is able to determine the postural position of a patient [25], [26].

Kinect-based recovery systems have been developed for analyzing rehabilitation exercises done by the patient. One such system simply compares the exercises made by the patient with a videotape of a physical therapist who perform these exercises [27]. This system is totally inflexebil because they can not achieve changes to the exercise plan.

By using the Kinect system, applications were developed to assess Up and Go test which requires getting up from a chair and normal walking, 10 meter walk test and finally measuring the angles of movement of the upper limbs [28].

In the field of motor recovery there are multiple complex applications based on Kinect [29-32]. These systems are used to help the patient to rehabilitate his upper limbs in terms of neuromotor point of view. Also in this field of neurological recovery, a set of recreational games "Kinect Adventures" conducted by Microsoft has given very good results in the rehabilitation of patients with Parkinson's disease [33].

To analyze the patient posture from these spatial data of the joints we have to extract data about the angles at certain joints that are of interest and height from the ground of these joints.

For analysis of lateral axial deviation of the spine we have to analyze spatial position of the shoulders and hips which are key indicators of the spine axial deviation. To determine the height at which the hips and shoulders are it is enough to extract data related to the height from raw spatial data. To determine the asymmetry between the joints of the shoulders or hips we can analyze the angle made by the two extremities, specifically the angle made by the right shoulder with the left shoulder. This angle is calculated using the two vectors method. Using this algorithm from the neck joint we represent two vectors, one for the right shoulder and one for the left shoulder and we obtain the angle made by the two vectors at the origin point. In the same way we can achive the 
asymmetries identification at the hips. In this case the point of origin for the two vectors will be the middle of the basin. The algorithm that implements this method is shown using the mathematical formulas below:

$$
\begin{gathered}
A \bullet B=(A x \bullet B x+A y \bullet B y) \\
|A|=\sqrt{A x \bullet A x+A y \bullet A y} \\
\text { theta }=\cos ^{-1}\left(\frac{A \bullet B}{|A||B|}\right)
\end{gathered}
$$

Where $\mathrm{A}$ and $\mathrm{B}$ are the two joints of interest, $A_{x}, B_{x}, A_{y}, B_{y}$ are the cartesian coordinates of the joints and theta. Correlating these angles with spatial data we can identify if axial deviation is on the right or on the left side. Using the equations above we can achieve dynamic measurements to determine the chest movement degrees on different axes.

The raw measurements are saved into a digital CSV type file which contains following: unique anonymized identifier, age, sex, weight, height, BMI (body mass index), height of the shoulders and the difference between the two shoulders, the angle of the shoulders at the neck, rotation of the shoulders and the same properties for the hips.

\section{Results and discussions}

To analyze the collected data and detect if the elementary school students may have a malicious standing posture like hyper-kyphosis and scoliosis the difference of the height and rotation of the shoulders and hips were compared. It has been found from our measurements that these are the best indicator of the mentioned malicious postures.

From the first measurements at the beginning of the study it has been found that almost all of the participants in the study presents the symptoms of malicious posture by having some kind of asymmetry at the shoulder and hip levels. The most affected are the children between the ages of 12 and 14. The lack of physical exercises and long sitting hours in a non-ergonomic siting position has caused severe differences between the heights of the shoulder. The difference of height at the shoulder level can be a clear indication that the students wear their backpacks on one shoulder or an abnormal sitting position where the student is leaning to the right or to the left

side because it does not have a clear line of sight to the board. The rotation difference can be an indication of a rotated sitting position during classes.

These asymmetries can be observed on the figures below on series 1 which shows a clear presence of some kind of malicious posture.

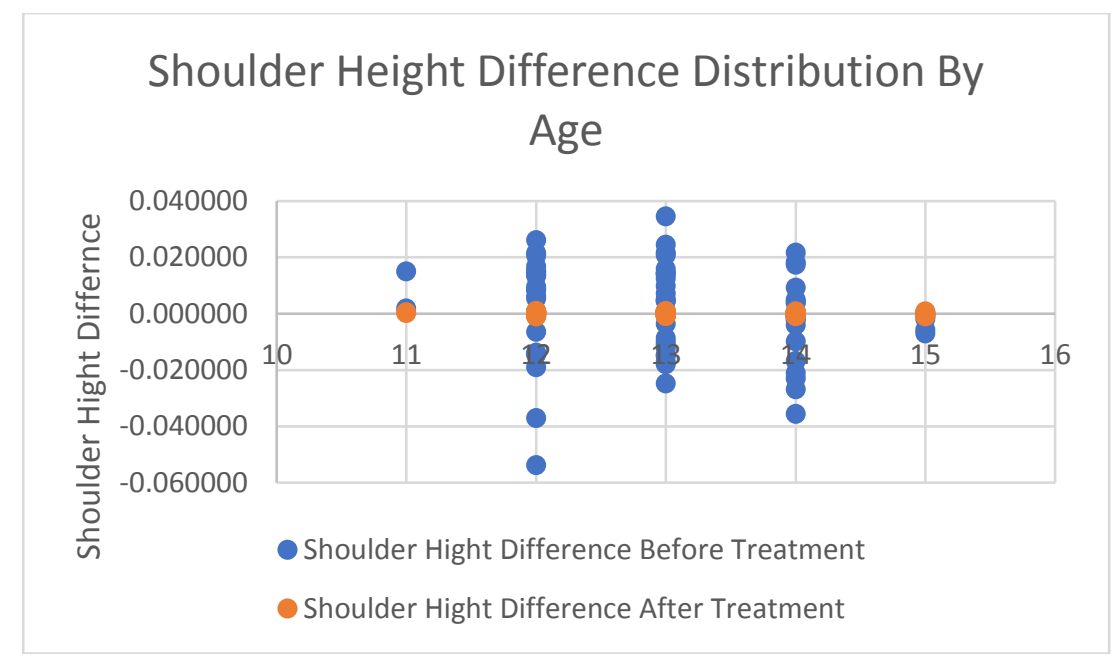

Fig. 2. Shoulder Height Difference Distribution By Age 


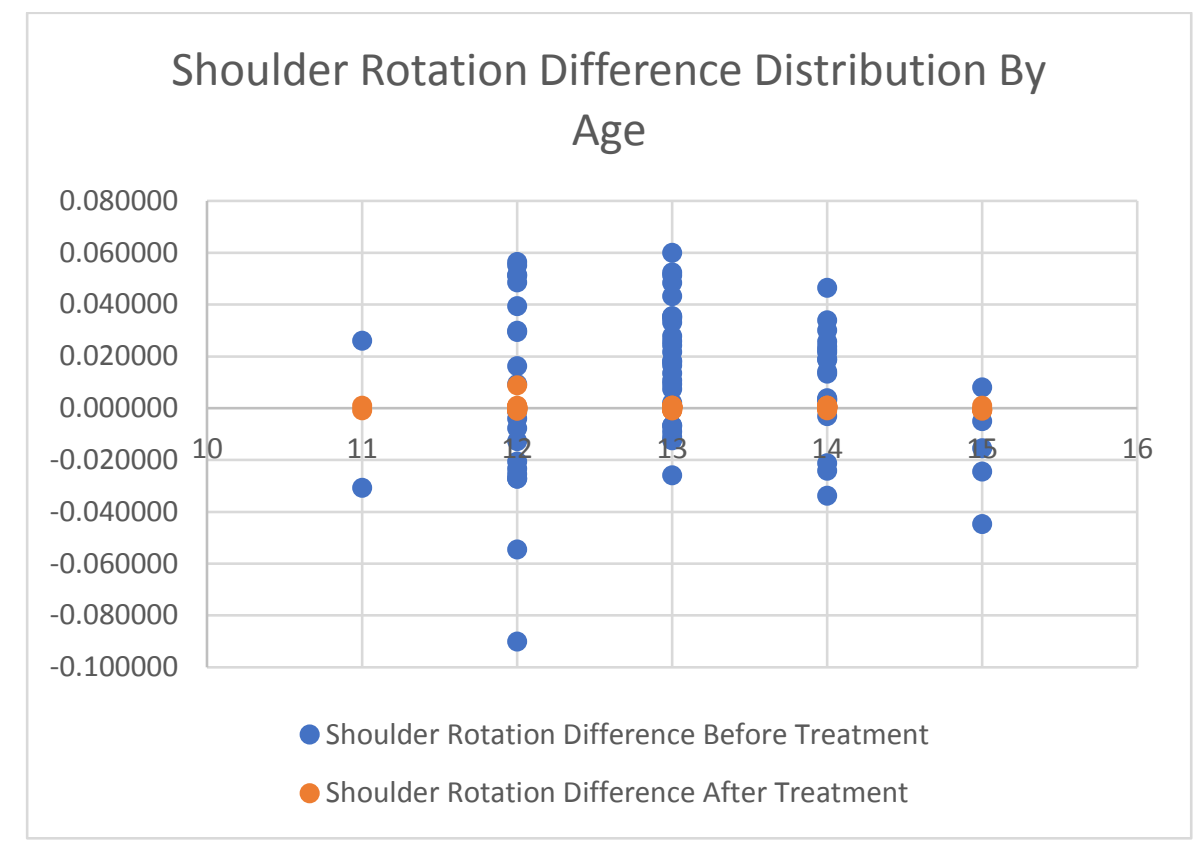

Fig. 3. Shoulder Rotation Difference Distribution By Age

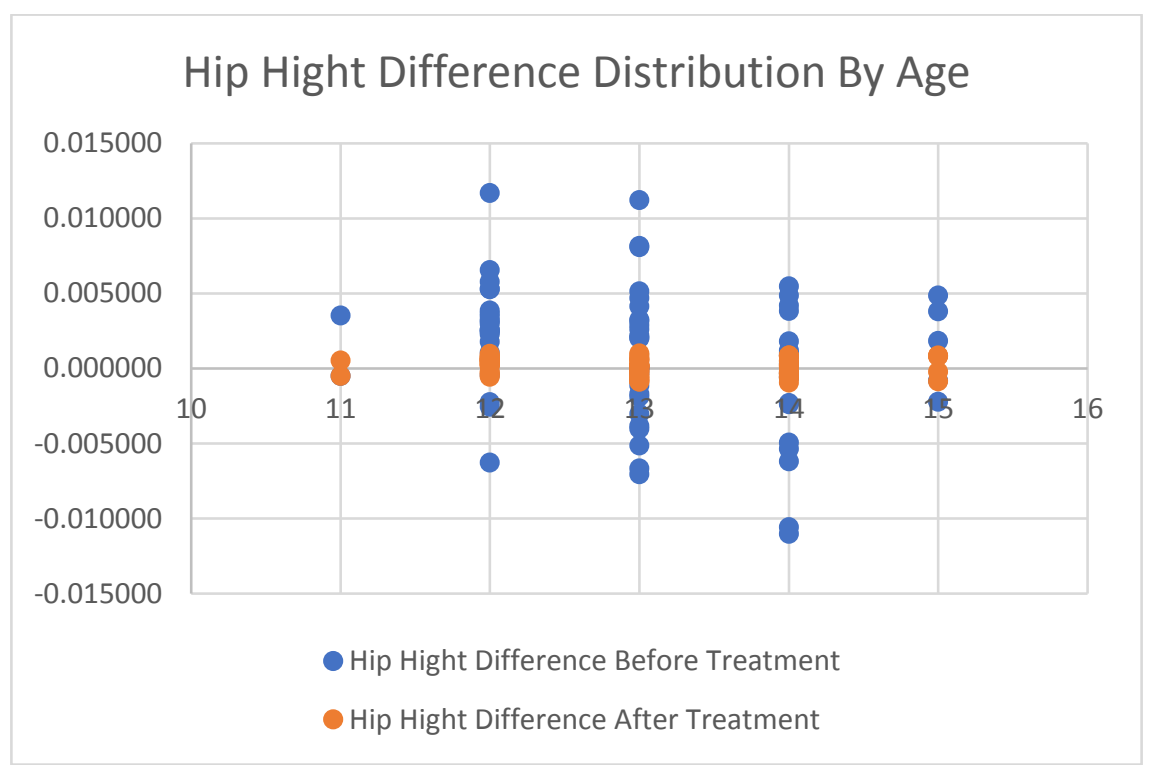

Fig. 4. Hip Hight Difference Distribution By Age 


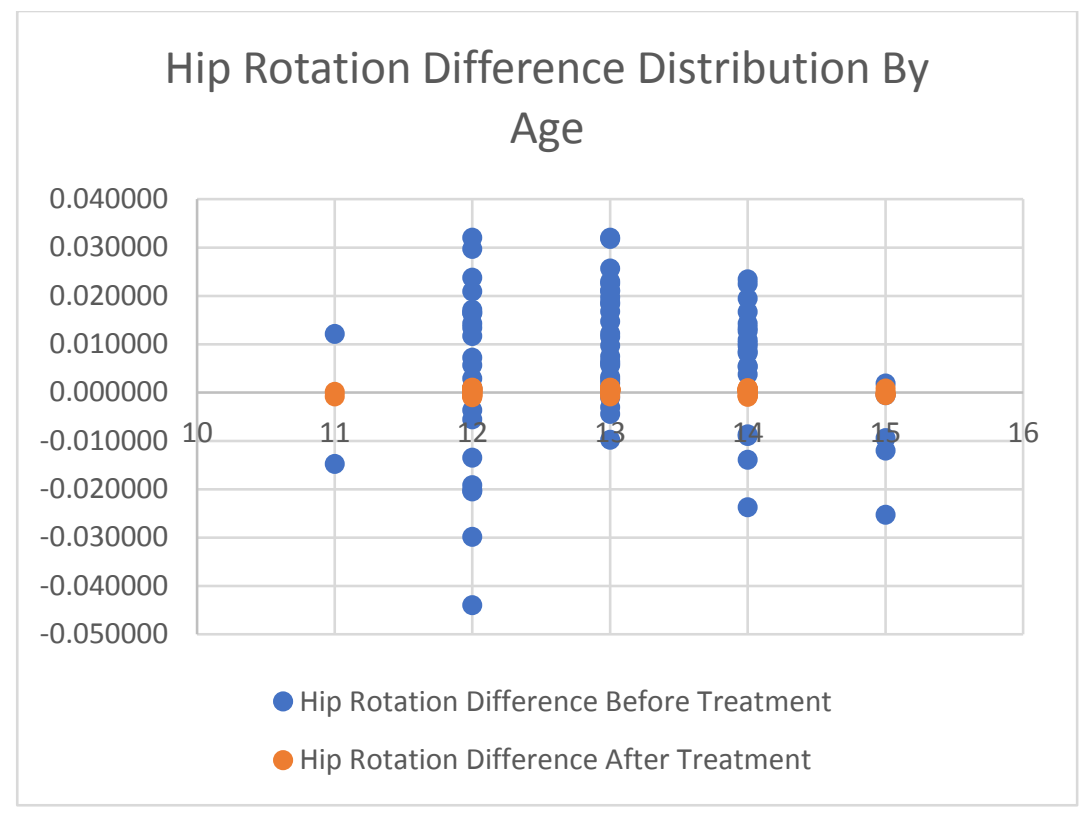

Fig. 5. Hip Rotation Difference Distribution By Age

After two teaching semester the study group was reevaluated using the same scanning method. The results are shown on the same figures in series 2. The results show that the treatment based on Schroth exercises were effective. The differences were reduced to a bare minimum.

One of the major factors for these results were the young age of the study group and the early stage of the malicious posture. At this young age the children have a higher healing capacity then the adults. In early stage of development of the malicious postures only the muscle memory is affected without any impact on the vertebrae. By correcting the posture and reeducating the muscle memory the posture of the young children can be significantly improved.

\section{Conclusions}

The spinal column is the axial support for the human body and influences it's posture. Several external factors, mostly incorrect siting positions for long hours can modify the correct anatomical curvatures of the spinal column. If these curvatures are modified hyper kyphosis, hyper lordosis and scoliosis can appear. On a long-term basis these modifications can impact in a negative way the spinal column and a person's general health. One indication of these modified curvatures is an incorrect standing up position. These incorrect standing up positions can be observed even from young ages, by analyzing the postures using the presented method. Our findings show that long sitting hours in the school benches in incorrect positions is affecting the overall standing up position of the children and can cause hyper kyphosis and scoliosis.

Our results have shown that at children due to their increase healing capacity early recognition combined with physiotherapy applied twice a week for 14 weeks can significantly reduce the negative affect of the long sitting hours to a bare minimum. This can be achieved due to the fact that at this age the vertebrae did not suffer any permanent damage and by reeducating the muscle memory from the upper body the forming of malicious posture is stopped and the body posture is corrected. This reduces the chances of the development of malicious body postures to a bare minimum..

The prevention and early correction.

\section{References}

1.VISHY MAHADEVAN, Anatomy of the vertebral column, Surgery (Oxford), Volume 36, Issue 7, 2018, Pages 327-332, ISSN 0263-9319, https://doi.org/10.1016/j.mpsur.2018.05.006

2.ELLA BEEN, LEONID KALICHMAN, Lumbar lordosis, The Spine Journal, Volume 14, Issue 1, 2014, Pages 87-97, ISSN 1529-

9430,https://doi.org/10.1016/j.spinee.2013.07.464.

3.PETER R. LOUGHENBURY, ATHANASIOS I. TSIRIKOS, Scheuermann's kyphosis: diagnosis, presentation and treatment, Orthopaedics and Trauma,Volume 31, Issue 6, 2017,Pages 388-394,ISSN 1877-1327, https://doi.org/10.1016/j.mporth.2017.09.010. 
4.UMBERTO DE GIROLAMI, TEJUS A. BALE, Chapter 29 - Spinal cord, Editor(s): Gabor G. Kovacs, Irina Alafuzoff, Handbook of Clinical Neurology, Elsevier, Volume 145, 2018, Pages 405-425, ISSN 0072-9752, ISBN 9780128023952, https://doi.org/10.1016/B978-0-12-8023952.00029-8

5.SELCUK PALAOGLU, OMER AKKAS, AYDIN SAV, Chondroma of the cervical spine, Clinical Neurology and Neurosurgery, Volume 90, Issue 3, 1988, Pages 253-255, ISSN 0303-8467, https://doi.org/10.1016/0303-8467(88)90032-7.

6.N.D.E. GREENE, A.J. COPP, Spina Bifida, Reference Module in Life Sciences, Elsevier, 2017, ISBN 9780128096338, https://doi.org/10.1016/B978-0-12-809633-8.07194-6.

7.POSTERIOR ARCH RACHISCHISIS, Editor(s): Jeffrey S. Ross, Bernard R. Bendok, Jamal McClendon, Imaging in Spine Surgery, Elsevier, 2017, Page 92, ISBN 9780323485548,

8.Gavriliu ST, Ghiță RA, El Nayef T, Burnei A, Olaru-Barbilian CR. Burnei's disease: teratological spondylolysis. J Med Life. 2015 Oct-

Dec;8(4):432-5.

9.CARLO ORZINCOLO, GIUSEPPE CASTALDI, PIER NUCCIO SCUTELLARI, Platyspondyly in treated beta-thalassemia,European Journal of Radiology, Volume 18, Issue 2, 1994, Pages 129-133, ISSN 0720-048X, https://doi.org/10.1016/0720-048X(94)90280-1.

10.Zaharia C, Scolioza, Editura medicală, 1980

11. SHAHNAWAZ H., COLIN N., Scoliosis: a review, Paediatrics and Child Health, Volume 28, Issue 5, 2018, Pages 209-217, ISSN 1751-7222, https://doi.org/10.1016/j.paed.2018.03.007

12. WANG, EDWARD D., DRUMMOND, DENIS S., DORMANS, JOHN P., MOSHANG, THOMAS M.D., DAVIDSON, RICHARD S.,

GRUCCIO, DENISE.,Scoliosis in Patients Treated with Growth Hormone,Journal of Pediatric Orthopaedics:November/December 1997 - Volume 17

- Issue 6 - pp 708-711

13. STOKES A.F.I., Mechanical effects on skeletal growth,J Musculoskel Neuron Interact 2002; 2(3):277-280

14.FRANK P CASTRO, Adolescent idiopathic scoliosis, bracing, and the Hueter-Volkmann principle, The Spine Journal, Volume 3, Issue 3, 2003, Pages 180-185, ISSN 1529-9430, https://doi.org/10.1016/S1529-9430(02)00557-0

15.GOLDSTEIN, WAUGH, Classification and Terminology of Scoliosis,Clinical Orthopaedics \& Related Research:June 1973 - Volume 93 - Issue ppg 10-22

16.McMASTER M. J.; OHTSUKA K.,The natural history of congenital scoliosis. A study of two hundred and fifty-one patients,J Bone Joint Surg Am, 1982 Oct; 64 (8): 1128 -1147

17. CONNOR J. M., CONNER A. N., CONNOR R. A. C., TOLMIE J. L., YEUNG B., GOUDIE D. JAMES F. Reynolds,Genetic aspects of early chiidhood scoliosis, American Journal of Medical Genetics, Volume 27, Issue 2, pages 419-424, June 1987

18. Dobbs B. M., Weinstein L.S.,Infantile and juvenile scoliosis, Orthopedic Clinics of North America, Volume 30, Issue 3, 1 July, Pages 331-341 19. MAYER O. H. Scoliosis and the Impact in Neuromuscular Disease,Paediatric Respiratory Reviews, Volume 16, Issue 1, January 2015, Pages 3542.

20. DAVIES J. E., GIBSON T., TESTER L., The Value Of Exercises In The Treatment Of Low Back Pain, Rheumatology (1979) 18 (4): $243-248$ 21. ZAMORA E., MACRAŞ-OSORHEAN D. M., TRIF I. M., MAN C. A. The importance of kinesiotherapy in equilibrating and correction of the scoliosis of third degree at puberty -- case study --, Educatio Artis Gymnasticae

22. ${ }^{* *}$ https://www.dataprotection.ro/servlet/ViewDocument?id=1442 (accesed 25-05-2018)

23.CHRISTA LEHNERT-SCHROTH, Introduction to the Three-dimensional Scoliosis Treatment According to Schroth, Physiotherapy, Volume 78, Issue 11, 1992, Pages 810-815, ISSN 0031-9406, https://doi.org/10.1016/S0031-9406(10)60451-8

24.JOSÉ LUÍS PIMENTEL DO ROSÁRIO, Biomechanical assessment of human posture: A literature review, Journal of Bodywork and Movement Therapies, Volume 18, Issue 3, July 2014, Pages 368-373, ISSN 1360-8592,

25.ROSS A. CLARK, YONG-HAO PUA, KARINE FORTIN, CALLAN RITCHIE, KATE E. WEBSTER, LINDA DENEHY, ADAM L.

BRYANT, Validity of the Microsoft Kinect for assessment of postural control, Gait \& posture 1 (2012) s 372-377

26.NERI, L.; ADORANTE, G.; BRIGHETTI, G.; FRANCIOSI, E., Postural rehabilitation through Kinect-based biofeedback, Virtual Rehabilitation (ICVR), 2013 International Conference on (2013), 218,219

27.CHUAN-JUN SU, CHANG-YU CHIANG, JING-YAN HUANG, Kinect-enabled home-based rehabilitation system using Dynamic Time Warping and fuzzy logic, Applied Soft Computing, Volume 22, September 2014, Pages 652-666, ISSN 1568-4946,

28.KITSUNEZAKI, N.; ADACHI, E.; MASUDA, T.; MIZUSAWA, J., KINECT applications for the physical rehabilitation, Medical Measurements and Applications Proceedings (MeMeA), 2013 IEEE International Symposium on , vol., no., pp.294,299, 4-5 May 2013

29. YAO-JEN CHANG, WEN-YING HAN, YU-CHI TSAI, A Kinect-based upper limb rehabilitation system to assist people with cerebral palsy, Research in Developmental Disabilities, Volume 34, Issue 11, November 2013, Pages 3654-3659

30.D. GONZÁLEZ-ORTEGA, F.J. DÍAZ-PERNAS, M. MARTÍNEZ-ZARZUELA, M. ANTÓN-RODRÍGUEZ, A Kinect-based system for cognitive rehabilitation exercises monitoring, Computer Methods and Programs in Biomedicine, Volume 113, Issue 2, February 2014, Pages 620631 ,

31.FUNAYA, H.; SHIBATA, T.; WADA, Y.; YAMANAKA, T., "Accuracy assessment of kinect body tracker in instant posturography for balance disorders," Medical Information and Communication Technology (ISMICT), 2013 7th International Symposium on , vol., no., pp.213,217, 6-8 March 2013

32.BERNHARD MAURER, FABIAN BERGNER, PETER KOBER, RENE BAUMGARTNER, "Improving rehabilitation process after total knee replacement surgery through visual feedback and enhanced communication in a serious game", Proceeding SIGDOC '12 Proceedings of the 30 th ACM international conference on Design of communication, Pages 355-356,

33.J.E. POMPEU, L.A. ARDUINI, A.R. BOTELHO, M.B.F. FONSECA, S.M. ALVARENGA, ANTI POMPEU, C. TORRIANI-PASIN, J.E. Deutsch, Feasibility, safety and outcomes of playing Kinect Adventures!TM for people with Parkinson's disease: A pilot study To appear in: Physiotherapy, Received date: 13-5-2013, Accepted date: 14-10-2013

Manuscript received: 6.11 .2019 